\title{
Some Phonological Processes in an Akan Linguistic Game*
}

\author{
Kwasi Adomako (Winneba)
}

\begin{abstract}
This paper examines some phonological processes observed in the Pig Latin; a linguistic game played in Akan, a Niger-Congo (Kwa) language. The Akan Pig Latin (henceforth APL), which is popularly known as Megesege is usually played among Akan youth. The purpose of this game varies from concealment to social identity establishment. This paper is a qualitative study of 200 stimuli of sentences in regular Akan constructions manipulated into the APL. The simple rule for playing the game is to syllabify an already existing word and to add a [CV] syllable to each of those segmented syllables. Through this manipulation of existing word, several phonological processes are observed including insertion, syllabification, palatalization etc. The paper presents a descriptive analysis of some of the processes and shows how the study of the APL can facilitate our understanding of the several phonological phenomena in Akan, even though it may display, in many parts, quite different patterns from what obtains in the regular Akan grammar.
\end{abstract}

\section{Introduction}

Linguistic games or Language games as alternate languages are a common phenomenon and have been well studied cross-linguistically by several researchers (cf. Haas 1957, 1967, 1969; Sherzer 1970, 1985; Decamp 1970; Conklin 1956, 1959; among others). The linguistic games come in different forms or types and in this current paper, I will focus the discussion on one form; the Pig Latin played in Akan, which is locally termed Megesege. In Akan, the phenomenon has received very little scholarly attention and the only readily available materials are by Kofi Agyekum (1996, 2009). It used to be a very common game in many Akan communities some few decades back, but now it seems the number of its players is gradually waning, especially in the urban areas and among the younger generation. Its gradual lost of popularity may be attributed to some socio-cultural as well as economic factors such as urbanization, westernization etc. (cf. Agyekum 2009). Perhaps, this situation may be responsible for the reason why there is very limited scholarly literature available on the subject in Akan. In the study of this phenomenon in Akan, researchers have, to a large extent, limited their scope to the ethnography and sociolinguistics of game, however, judging from

\footnotetext{
* I would like to express my profound appreciation to the anonymous reviewers of this paper for their invaluable comments and suggestions. I would also like to acknowledge the very useful comments from Hannah Sande at the initial stages of the preparation of this paper. However, any shortcoming that might be detected in this paper is solely mine.
}

Linguistik online 72, 3/15- http://dx.doi.org/10.13092/lo.72.1970

CC by 3.0 
the wide interest data on linguistic games present in facilitating our understanding of several phenomena in linguistic components such as morphology, phonology, sociolinguistics, pragmatics etc., the current paper seeks to extend the linguistic coverage the phenomenon has received in Akan to the domains of phonology.

In the phonological analysis of the game, for instance, it would be shown that some debates in the literature such as syllabification of especially CrV stems (cf. Schachter/Fromkin 1968; Abakah 2004; Dolphyne 2006; Marfo/Yankson 2008; Marfo 2013) could be well resolved by reference to the study of how players of the game manipulate existing $\mathrm{CrV}$ words. In addition to this, this paper will attempt to enlighten us about the pattern of some phonological processes such as palatalization and finally insertion of CV syllable inside an existing word or morpheme, which is an uncommon type of insertion in Akan and show what conditions such a process.

\subsection{Background of Akan}

Akan is a member of the Niger-Congo (Kwa) family of languages. It is spoken mainly in Ghana and some parts of Côte d'Ivoire both in West Africa. The language has several dialects, but among these dialects, the three major ones which have received literacy status and are taught in schools are Akuapem, Asante and Fante. Both the Akuapem and the Asante dialects together constitute the Twi group of Akan. According to the recently conducted national Population and Housing Census, over $40 \%$ of Ghanaians speak the language as their L1 and together with its non-L1 speakers, it is estimated that more than half of Ghana's over 24 million population ${ }^{1}$ either speak or understand the Akan language. This makes the Akan language the most widely used language in Ghana today particularly for education, commerce and in the media.

In terms of its segment inventory, Akan has ten phonemic ${ }^{2}$ vowels in its vocalic system which I present below in (1). The vowels are in their contrastive pairs in terms of Advanced Tongue Root (ATR) values.

\begin{tabular}{cccc}
\multicolumn{2}{c}{ Akan vowel chart } & & \\
& Front & Central & Back \\
High & i, I & & u, $\mho$ \\
Mid & e, $\varepsilon$ & & o, o
\end{tabular}

Low

æ, a

Akan operates an open syllable system with the following as its basic syllable structures; $\mathrm{CV}$, $\mathrm{V}$ and $\mathrm{C}$ where the $\mathrm{C}$ is invariably [+sonorant]. Other structures such as $\mathrm{C}_{1} \mathrm{C}_{2} \mathrm{~V}^{3}$ can be derived at the surface representation.

\footnotetext{
1 From the 2010 Population and Housing Census conducted, it is now estimated that Ghana's population is about 24,6 million.

2 While the Twi dialects, especially the Asante dialect, operate ten-vowel system, many varieties of the Fante dialect, on the other hand, have nine phonemic vowels in their system. The low vowel /æ/ occurs in some subdialects of the Fante dialect (cf. Abakah 2004, 2005, 2013), though according to Lawrence Addai Boadi (2009: 6-11), it seems to be losing its contrast with its counterpart, /a/ in Akan in general.
} 
According to Florence Abena Dolphyne (2006: 52), the syllable in Akan can also be described in terms of the tone on which the consonant and/or vowel, which makes up the syllable, is uttered. Syllables in Akan never end in coda (cf. Dolphyne 2006; Abakah 2005, 2004). But syllabic consonants such as $\mathrm{m}, \mathrm{n}, \mathrm{r}, \mathrm{w}$, can be tone-bearing. This is exemplified in the following words in (2) and (3) on the Akan syllabification of NCV, CVN and CVV respectively.

$\begin{array}{lllll} & \text { Syllable structure } & \text { Word } & \text { Gloss } & \text { Ill-form } \\ \text { a. } & \text { N.CV } & \text { n.go } & \text { palm oil } & * \text { NCV } \\ \text { b. } & \text { CV.N } & \text { ta.m } & \text { lift it } & * \text { CVN }\end{array}$

It is worth noting that in Akan all nasals can be syllabic except those that occur in pre-vocalic position. I will talk more about morpheme-final nasals in subsection 1.2. On vowels, Florence Abena Dolphyne (2006: 53-54) argues that each vowel in Akan constitutes a syllable, hence, a sequence of two vowels either of the same quality or of different qualities is counted as constituting two separate syllables. For example, the following words are represented in their respective syllable structure in (3).

$\begin{array}{lllll} & \text { Syllable structure } & \text { Word } & \text { Gloss } & \text { Ill-form } \\ \text { a. } & \text { CV.V } & \text { bu.a } & \text { respond } & * \text { CVV } \\ \text { b. } & \text { CV.V } & \text { ko.s } & \text { red } & * \text { CVV }\end{array}$

In summary, based on Dolphyne's (2006) claim about the constituents of Akan syllable structure, syllable structures such as; ${ }^{*} \mathrm{CVC}, * \mathrm{VC},{ }^{*} \mathrm{CCV},{ }^{*} \mathrm{CVV},{ }^{*} \mathrm{CVVC}$ etc. are not permitted in Akan. In subsection 1.2, we look at the morpheme-final nasal in Akan.

\subsection{Morpheme-Final Nasals in Akan}

On CVC syllable type in Akan, Emmanuel Nicholas Abakah (2005) argues that there can never be a word or syllable with final consonant (obstruent). This claim buttresses earlier assumptions made especially by Paul Schachter/Victoria Fromkin (1968), and Florence Abena Dolphyne (2006) that only [+sonorant] consonants such as nasals, labio-velar glide /w/ as in shaw'problem', and liquid /r/, which is usually found in Fante words such as kor'one', can occur word-finally (in the coda position) at the surface representation in Akan. Therefore, there cannot be any syllable of $\mathrm{C}_{1} \mathrm{VC}_{2}$ structure in Akan in which $\mathrm{C}_{2}$ is a [-sonorant] segment. In furtherance of his argument, Emmanuel Nicholas Abakah (idem.) posits that the archiphoneme /N/ has two realizations. This was a direct response to Paul Schachter/Victoria Fromkin's (1968) claim about the underlying final stops in Akan. While the underlying bilabial nasal stop surfaces as [m] in all the three dialects, the underlying alveolar nasal becomes [n] in the Fante dialect, [n] in the Akuapem dialect, but is replaced with a high vowel in the Asante dialect depending on the roundness of the stem vowel. On the final alveolar nasal realization in the Asante dialect, Emmanuel Nicholas Abakah (idem.) continues that the intervocalic alveolar nasal is deleted in Asante and they are replaced with [+high] vowels depending on the ATR value of the stem and roundness of the stem vowel in the

3 The $\mathrm{C} 2$ which manifests as $\mathrm{CrV}$ is found in native words such as sra 'visit', fre 'call', while the lateral sound /1/, on the other hand, is found in nativised words. 
surface representation. He further argues that the deleted nasal spreads its nasal feature to the epenthesized vowel before it finally deletes. The data in (4) and (5) are adapted from Emmanuel Nicholas Abakah (2005: 49). The UR stands for underlying representation which is used interchangeably with phonological representation in this paper, while SR stands for surface or phonetic representation.

$\begin{array}{llllll} & \text { UR } & \text { Fante } & \text { Akuapem } & \text { Asante } & \text { Gloss } \\ \text { a. } & \text { sinĩ } & \text { sĩn } & \text { sĩn } & \text { sĩi } & \text { not full, short } \\ \text { b. } & \text { dinĩ } & \text { dzĩn } & \text { dĩn } & \text { dĩi } & \text { strong, hard, difficult } \\ \text { c. } & \text { kanĩ } & \text { kãn } & \text { kan } & \text { kãĩ } & \text { count } \\ \text { d. } & \text { fon } & \text { fwõn } & \text { fw̃̃ } & \text { fwõ } & \text { to be emaciated }\end{array}$

The bilabial nasal is the same in all the three major dialects of Akan as follows in (5). Let us note that the underlying forms are monomorphemic, that is, each is composed of a single morpheme.

\begin{tabular}{|c|c|c|c|c|c|}
\hline & $\mathbf{U R}$ & Fante & Akuapem & Asante & Gloss \\
\hline a. & pamv & pãm & pãm & pãm & sew \\
\hline b. & $\operatorname{tam} v$ & tãm & tãm & tãm & lift \\
\hline$c$ & pĩmv & pĩm & pĩm & pĩm & to head-butt, crash into \\
\hline d. & bamv & bãm & bãm & bãm & embrace somebody \\
\hline
\end{tabular}

Aside from these nasals, the labio-velar glide /w/ is also permitted morpheme-finally in the Akuapem, Asante and Fante dialects, but the liquid /r/ is realized in the same position exclusively in the Fante dialect. In the UR, all morpheme-final nonvowel sonorants in Akan are followed by [+high] vowels, which delete in the SR. For detailed discussions on this, see Abakah, 2004, 2005 etc.

\subsection{Methodology}

This study is a qualitative examination of how regular Akan prosodic structures such as word, phrase and sentences are manipulated into the APL by the players of the language game. Through such manipulations, some phonological as well as morphological phenomena are observed in the APL. The data for the current study consist of two hundred (200) manipulated sentences in the APL, elicited from primary sources between 2012 and 2013 in both the Ashanti and the Central Regions of Ghana with a speaker recorded in each of the two regions. The two young male respondents ${ }^{4}$ served as language helpers who were consulted for this study and are both native speakers of the Asante Twi dialect of Akan. They were purposively selected as the respondents for this project primarily because they communicate almost exclusively in APL. The ages of the respondents were 18 and 25. I randomly selected sentence stimuli in the regular Asante Twi dialect for the respondents to manipulate into the

\footnotetext{
4 Even though the playing of the game is not restricted to male participants, the two respondents who happen to be brothers were selected for the purpose of the current study. More so, among the target respondents I earlier selected, these two demonstrated much fluency in the game, hence, their selection.
} 
Megesege game. The sentence stimuli comprised both simple and complex sentences. For example, I gave them simple sentences like, Kofi beks'Kofi will go', which both respondents manipulated it into [kogofigi begekogo]. For emphasis and also confirmation of the quality of the epenthetic segments, the respondents were asked to repeat each sentence thrice; the first two were said in normal casual speech context while the last repetition was made slowly. I recorded their responses using both a voice recorder and a notebook. I later analyzed the data that were recorded using the Praat software to determine the quality of the epenthetic segments, especially the epenthetic vowel.

\section{Linguistic Games in Akan}

As already mentioned in section 1, the language or linguistic game is one of the domains in language study that has been well studied across different languages families, namely English (Halle 1962), Estonian (Lehiste 1985), Burmese (Haas 1969), Jamaican Creole (Decamp 1970), Japanese (Sanches 1968), Cuna (Sherzer 1970), Tagalog (Conklin 1956), Thai (Haas 1957), Bakwiri (Hombert 1973), Akan (Agyekum 1996, 2009) etc. Language or linguistic games have several other names including speech play, speech disguise, word play, word game, linguistic play, secret language etc. I will use the terms language game and linguistic game interchangeably throughout the rest of the paper.

Kofi Agyekum (2009) has identified several kinds/types of speech play among the Akans including puns, riddle, tongue twisters, verbal dueling contest, mnemonic devices, Pig Latin, rhyme, quasi euphemisms, jokes, humours, linking and association etc. The use of any of these demonstrates the speaker's language competence and communicative artistry.

As Kofi Agyekum (2009: 48) postulates, "speech play is a universal concept, but its structure, form, rules and socio-cultural contexts vary from culture to culture" and the rules APL are no exception. Its use serves to fulfill some communicative purpose. Among the functions of playing this game, according to Kofi Agyekum (2009: 73) is that, "it fosters and reinforces group identity and [also] brings about social cohesion and good interpersonal relationship among people [who play the games]."

Since it is an in-group language game, it is played usually when gossiping or when using vulgar language, which society frowns upon. This serves as the concealment function of the game, which has already been pointed out. It is also played to establish group identity. Apart from it being used to cover up "filthy talk", or obscene language, it is also used as a cover up for one who is in trouble.

\subsection{The Akan Pig Latin}

The common Akan term for Pig Latin is megesege/mekeseke, which in itself is a manipulated form of the clause mese which means 'I say...'. The name perhaps suggests its concealment or gossip function. Megesege is a language game meant for only the trained ears who are predominantly the youth, though it is not as vibrant as it used to be as has already been pointed out. Since in playing the game, all regular words or morphemes are segmented into their respective syllables and each syllable is affixed with $[\mathrm{g}+\mathrm{V}]$, it makes it difficult for the untrained ears to comprehend the import of such a conversation or speech. For instance, a CV syllable comprising a sequence of a back consonant $/ \mathrm{k}, \mathrm{g} /+\mathrm{a}$ front vowel sequence is marked 
in the regular phonology of Akan. Even more interesting is the observation that a highly marked syllable structure in terms of the language's phonotactics, such as the use of the syllable-initial clusters such as $s k, s p, s t, g s$ etc. as were discussed in (3), emerges in the game.

\subsubsection{Forms of Akan Pig Latin}

The APL comes in more than one variety and so far about five (5) common varieties can be identified among Asante Twi players of the game which are as follows in (6).

\section{Varieties of Akan Pig Latin}
a. Megesege/mekeseke
b. Mepresepre
c. Mesteseste
d. Mesesese
e. Megsesegse

Unlike in Cuna games where the different forms of the game reflect differences in dialect (cf. Sherzer, 1970), the variation in the APL does not reflect dialectal differences or even subdialects, but just preferences for a particular variety of the game by the players themselves. The different forms pattern the same ways; they follow the same morphological and phonological rule applications.

Though any of the varieties in (6) above can be used to express the same clause mese'I say...', the present study will focus on the form in (6a); Megesege which has [g/k] $+[\mathrm{V}]$ affixed to each segmented syllable preceding it. The main reason for this choice is simply because it is the most popular variety.

\subsubsection{Rules for playing Akan Pig Latin}

Unlike in many other languages such as Cuna (cf. Sherzer 1970; among others) where the rules for playing linguistic games such as backward speaking involve shifting or swapping the position of syllables (cf. Agyekum 2009), in the Akan linguistic game (Pig Latin), the rule is that you suffix a consonant (C) to a segmented syllable. The ensuing $\mathrm{CV}+\mathrm{C}$ or $\mathrm{V}+\mathrm{C}$ structure would violate Akan syllable structure as was discussed in (3), nonsonorant Cs are not allowed in final position. To correct this structural ill-formedness, the syllable-internal vowel (V) of the preceding segmented syllable spreads rightwards to prevent coda at the surface level of representation. The description of the rules for playing the APL game is ordered as follows; 
The 3-step rules for playing the game ${ }^{5}$ :

(i) First, syllabify every existing word or morpheme. (The syllabification strictly adheres to the basic syllables structures of Akan as was discussed in (1)).

(ii) Second, suffix $[\mathrm{g}]$ to each of the preceding segmented syllable.

(iii) Finally, spread the syllable-internal V of the segmented syllable to the end of the epenthetic $[\mathrm{g}]$.

The epenthetic V is invariably a complete copy of the preceding syllable-internal vowel, which controls the height, roundness and ATR values of the former vocalic segment. For example, the syllable-internal vowel in a word like $p \varepsilon^{\prime}$ to like' is the front mid vowel $/ \varepsilon /$ - you simply add $[\varepsilon]$ to $[\mathrm{g}]$ and realize $g \varepsilon$. So the regular word $p \varepsilon$ is manipulated into $p \varepsilon g \varepsilon[\mathrm{p} \varepsilon \mathrm{g} \varepsilon]$ in the APL. Similarly, when the existing word is disyllabic, each syllable ends in $[\mathrm{g}+\mathrm{V}]$. For example, mese'I say' is manipulated into megesege [migIsigI] in the APL.

As already pointed out, players select only one syllable at a time and usually attach $[\mathrm{g}+\mathrm{V}]$ to its end, however, the insertion takes on a different form when the target word for manipulation ends in a nasal consonant as in CVN. In such cases, the epenthetic syllable no longer attaches to the end of the segmented syllable, but instead inserted inside the existing word; the nasal now becomes final syllable of the manipulated word. For example, the regular form menim'I know' becomes mege-nigim [migi-nigim] in its manipulated form. I shall further elaborate on this in subsection 3.5.

\section{Some phonological processes in the APL}

The APL exhibits several phonological patterns expected from the grammar of regular speech in Akan.

In playing the game, lexical items, phrasal word as well as sentential words are segmented into individual morphemes including all functional morphemes such as negation, number etc. Each of these morphemes is then syllabified before an epenthetic [CV] syllable is inserted into it as discussed in the previous subsection.

In the course of playing this linguistic game, there are several phonological processes observed including syllabification, palatalization, and insertion. In the subsequent subsections, I discuss each of these phonological processes with examples from the APL and show how they can contribute to our understanding of several phonological phenomena and their theorizations.

5 These steps would result in the same epenthetic [gV] as those proposed by Kofi Agyekum (2009: 61) with the only difference between the two being in the order of application of the rules for playing the game. While Kofi Agyekum (idem) postulates the spreading of the syllable-internal V first before the epenthesis of [g], which I think, to a larger extent, has less motivation, my claim is that by first attaching $[\mathrm{g}]$ to a segmented $\mathrm{CV}$ or $\mathrm{V}$ syllable, it would result in illicitness in structure i. e. nonsonorant consonant in the coda position of the syllable. This would then necessitate a repair which could be done through the spreading the syllable-internal $\mathrm{V}$ to the end of the epenthetic $[\mathrm{g}]$. 


\subsection{The Akan Syllabification}

From the discussion in subsection 2.1.2, it was realized that the first step in manipulating an existing word or morpheme when playing the APL is by syllabifying an existing word or morpheme. For this reason, the APL facilitates our understanding of what constitutes the Akan syllable, particularly with regard to the $\mathrm{CrV}$ words or morphemes and the issue of diphthongization in Akan.

The actual UR of the Akan surface CrV morphemes or words has not been exhaustively dealt with by Akan phonologists though many of them, including Schachter \& Fromkin (1968), Dolphyne (2006), Abakah (2004), Marfo \& Yankson (2008), Marfo (2013) etc. postulate that any surface $\mathrm{CrV}$ morpheme or word is $\mathrm{CV}_{1} \cdot \mathrm{rV}_{2}$ in the phonemic representation, where $\mathrm{V}_{1}$ is specified with [+high]. The $\mathrm{V}_{1}$ usually deletes at the phonetic level of representation especially in casual or fast speech, hence, $\mathrm{CrV}_{2}$ is disyllabic with the ensuing surface syllable structure; $\left[\mathrm{Cr} . \mathrm{V}_{2}\right]$. This presupposes that the first syllable loses its nucleus and through resyllabification, the onset of the second syllable assumes the nucleus position of the first syllable at the SR. These scholars have used examples from several domains excluding the linguistic games to buttress their claim. In this paper, I contribute to this subject by providing data from the domain of the APL in support of this claim.

In playing the game, all existing $\mathrm{CrV}_{2}$ words are manipulated by inserting a high front vowel, which is the default vowel in Akan, to break up the seeming cluster into $\mathrm{CV}_{1} \mathrm{gV}_{1} \mathrm{rV}_{2} \mathrm{gV}_{2}$ where $\mathrm{V}_{1}$ is systematically prespecified with [+high, +front]. This epenthesis, it is claimed in this paper, is a result of default vowel insertion since it is not part of the segments of the existing word but only surfaces in the manipulated word to repair an illicitness that the addition of the epenthetic $[\mathrm{g}]$ would have caused. The motivation for this insertion, inter alia, could be as follows; first for 'cluster' reduction, and then for the subsequent ease of manipulation by players of the game. This is exemplified in (7).

\subsubsection{Syllabification of CrV words ${ }^{6}$}

\section{CrV structure}

\begin{tabular}{|c|c|c|c|c|c|}
\hline Mege & $\operatorname{kegelaga}^{7}$ & aganigi & aga & -gyege & ${ }^{*}$ megekaga -laga \\
\hline$[\mathrm{mig}$ & kigilaga & aganigi & aga & -dbIgI] & \\
\hline $\mathrm{Me}$ & kra & ani & $\mathrm{a}$ & -gye & \\
\hline 1SG.GEN & soul & eye & PRF & -collect & \\
\hline
\end{tabular}

\footnotetext{
6 As a convention in this paper, all data are presented in the standard Akan writing form or orthography with all examples in the bracket $[. .$.$] representing the phonetic variants. Also the target manipulated morphemes for our$ discussion are in boldface.

$7 \mathrm{It}$ is worth noting that Asante speakers most often freely vary the use of the following segments; $r, 1$, and $d$ in the regular phonology as evident in the Akan (Asante Twi) word for 'marriage'; aware which has three free

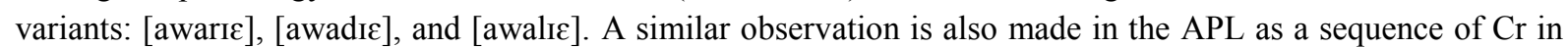
the segmented syllable, the $r$ is replaced with 1 in the manipulated forms.
} 


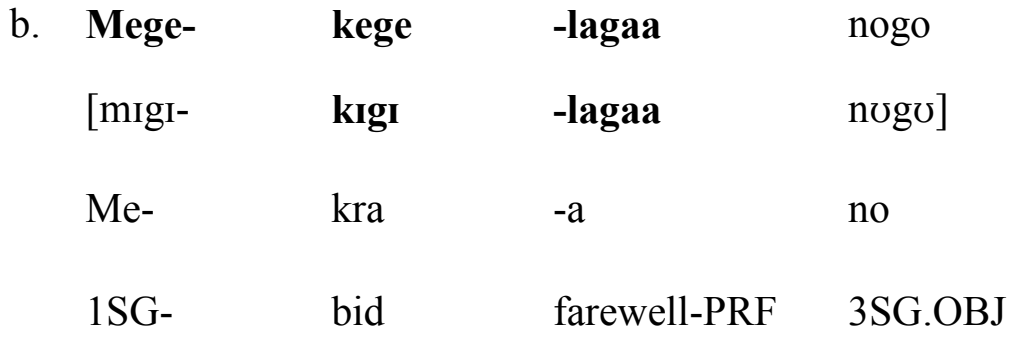

'I bid him/her farewell'

By the fact that there is a high vowel in the preceding syllable [mI-] in $(7 \mathrm{a}-\mathrm{b})$, one may be tempted to argue, from hindsight, that the epenthetic vowel insertion may have spread from the preceding vocalic segment and not as a result of default insertion. Now let us consider another example where there is no such preceding vocalic segment in $(7 \mathrm{c}-\mathrm{d})$.

\begin{tabular}{|c|c|c|}
\hline begelagaa $^{8}$ & kogofigi & bege-baga \\
\hline [bigılagaa & kogofigi & bege-baga] \\
\hline Braa & Kofi & $\mathrm{b} \varepsilon-\mathrm{ba}$ \\
\hline Brother & Kofi & FUT-come \\
\hline
\end{tabular}

'Bro. Kofi will come'

\begin{tabular}{|c|c|c|c|}
\hline Kyege & nogo & begeleg $\varepsilon$ & yєgєn \\
\hline [teIgI & nogv & bigIlege & jegen] \\
\hline Kye & no & bre & yen \\
\hline Catch & 3SG.OBJ & bring & 3PL.OF \\
\hline
\end{tabular}

'Catch him and bring him to us'

The pattern of manipulation in (7) is summarized in the following rule notation: $\mathrm{CrV}_{2} \rightarrow \mathrm{CV}_{1} \mathrm{gV}_{1} \mathrm{rV}_{2} \mathrm{gV}_{2}$.

From the examples in (7) above, it was observed that what Schachter \& Fromkin (1968), Dolphyne (2006) and Abakah (2004) have postulated to be the underlying vocalic segment that deletes in the phonetic representation i. e. the high vowel, emerges in the APL. In the regular phonology of Akan, the deleted high vowel re-emerges in slow or emphatic speech. In the APL, the deleted vowel systematically resurfaces in $\mathrm{CrV}_{2}$ words without concern for the rate of speech, as seen in the examples in (7) above.

\footnotetext{
8 It is interesting to note that in emphatic or slow speech, a source word brother, which does not have any inherent high vowel is realized as [brraa] in the Asante Twi dialect by some speakers. This is an extension of what happens in the regular phonology of the language where $\mathrm{CrV}$ is usually realized as $\mathrm{CVrV}$ in slow or emphatic speech (cf. Dolphyne 2006; Marfo/Yankson 2008; Marfo 2013).
} 


\subsubsection{Clusters}

Since the regular phonology of Akan neither has nor permits a cluster of obstruent sounds, any word found in the language with such a cluster is invariably a loan word. Adomako (2008) has observed that there are two main groups of loanword speakers in Akan; the monolingual speakers (who are mainly the illiterate older speakers) and the bilingual speakers (who are mostly the school-going youth). The former group, it has been observed, repairs every illicitness in the source words including clusters, while the latter group would usually adapted source clusters unrepaired (for further discussion of this, see Adomako 2008). What this implies is that the bilingual speakers permit clusters of consonants in the adapted words. Similarly, in the APL, it is observed that what the players of the game actually look for is not well-formedness in terms of structure of all the manipulated words, but mainly for the inserted $[\mathrm{g}+\mathrm{V}]$ to get $\mathrm{V}$ to copy from. Despite their absence in the regular Akan of older speakers, similar clusters are found in the manipulated forms by these young players of the game. Akan speakers usually repair such illicitness by reducing the clusters in two main ways; (i) by deleting one of the consonants or (ii) by inserting a vowel to break up the cluster. The latter repair strategy is most often employed. In (8a) an example of such a cluster typical of the young players of the game can be seen.

(8) CC Clusters

\begin{tabular}{|c|c|c|}
\hline sigistaga & yagaa & kogo \\
\hline [sigistaga & jagaa & kəgə] \\
\hline Sista & Yaa & ko \\
\hline Sister & Yaa & go \\
\hline
\end{tabular}

'Sister Yaa [is/has] gone'

As seen in (8a), a source cluster of st in the manipulated foreign word sister was observed, however, below in (8b), a similar source cluster of $p t$ is repaired by inserting a high vowel [I] in the manipulated form.

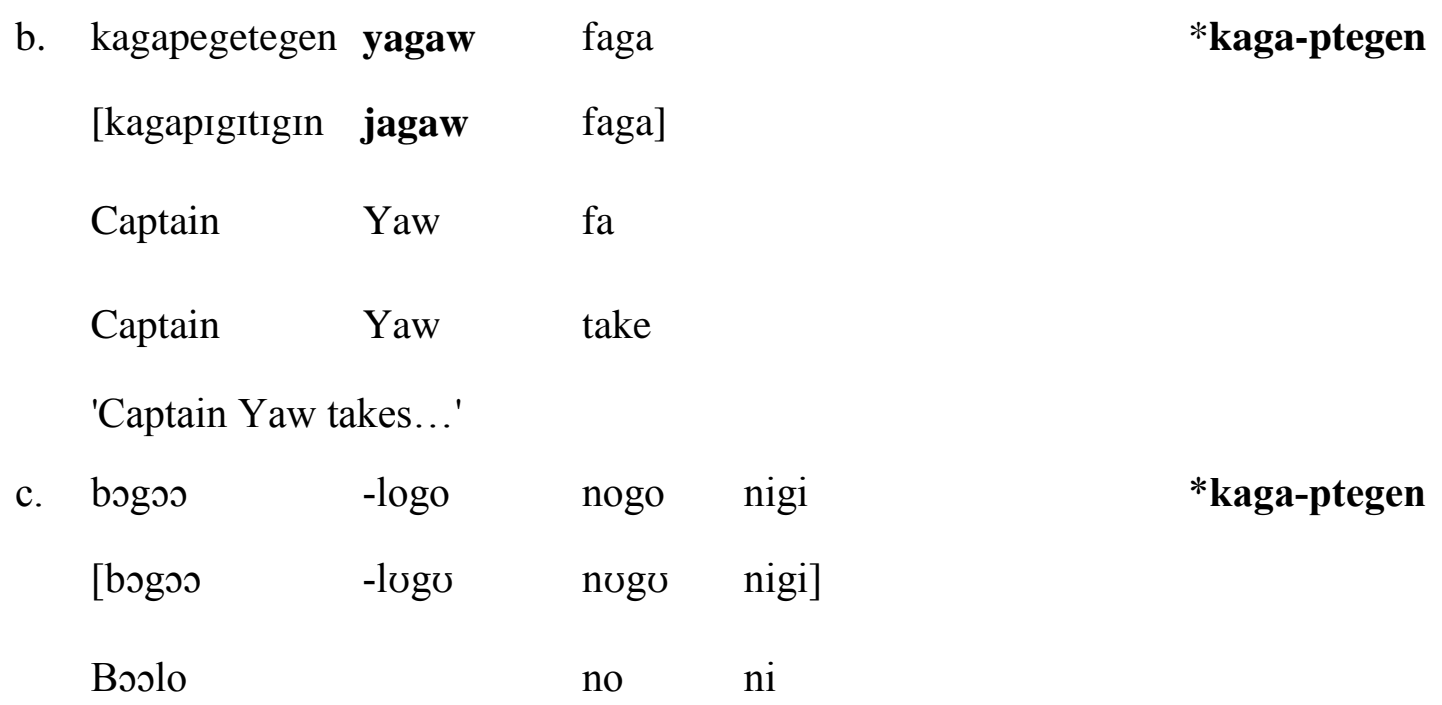


Football DEF here

'Here is the football'

It is worth noting in (10c) that the word football is most often shortened into ball in casual discourse by speakers of Akan, hence, the input word for manipulation is the shortened form but not the entire word football. With this background, it is evident that the input loaned form for manipulation in the game is without the word boundary cluster - $t b$ - as in the source word.

Having looked at how consonant clusters in loan words are adapted and manipulated in the APL, let us turn our attention to the discussion of manipulation of existing words or morphemes with vowel clusters (VV) in (9).

In the regular phonology of Akan, as was discussed in (3), a sequence of two vowels, either of the same quality or of different qualities, are considered to be in separate syllables in Akan. That is to say, Akan's phonological system does not include diphthongs. So all things being equal, it would have been expected that a word or morpheme with a cluster of two vowels will be manipulated by syllabifying it into two syllables, and the epenthetic [g+V] inserted into each of the two syllables. This, however, is not always the case as can be seen in the following examples in (9).

\section{(9) VV clusters}

\begin{tabular}{|c|c|c|c|c|}
\hline Ogo & $-p \varepsilon g \varepsilon$ & sege & ogo & -gyagae \\
\hline [ogo & $-p \varepsilon g \varepsilon$ & sege & ogo & -dzagai] \\
\hline 0 & $-p \varepsilon$ & $\mathrm{s} \varepsilon$ & 0 & -gyae \\
\hline $3 \mathrm{SG}$ & -like & COMP & $3 \mathrm{SG}$ & -stop \\
\hline
\end{tabular}

'S/he wants to stop'

\begin{tabular}{|c|c|c|c|c|}
\hline Wegei & $\mathrm{y} \varepsilon \mathrm{g} \varepsilon$ & mege & tigi-kyaga & ${ }^{*}$ wege-igi \\
\hline [yegei & $\mathrm{j} \varepsilon \mathrm{g} \varepsilon$ & migi & tigi-tcaga] & \\
\hline Yei & $\mathrm{y} \varepsilon$ & me & tikya & \\
\hline DEM & COP & 1SG.GEN & teacher & \\
\hline
\end{tabular}

'This is my teacher'

The phonetic [ar] in [dzar] as in (9a) is manipulated into [dagar]; monosyllable instead of the usually expected *[dagargI] as can also be seen in (9b). Similarly, [чei] is manipulated into [yegei], and not*[yegeigi] as would be expected. This can be explained by referring to the regular phonology of Akan where high vowels are not permitted word or morpheme-initially except in some few words in the Fante dialect. All the other vowels can occur elsewhere independently as in (9c-d) below showing [a] at the initial position. It is worth noting that the progressive marker - $r$ - is invariably deleted in the Asante and Akuapem Twi dialects of Akan at the surface representation. This deletion is compensated for by the lengthening of the 
immediately preceding vowel hence, its absence in the manipulated form. In other words, the input forms for manipulation in the APL are without the progressive marker.

$\begin{array}{lllll}\text { c. Mege } & -k \jmath g \jmath & \text { aga } & - \text { kogo } & \text {-faga } \\ {[\text { migI }} & -k \jmath g \jmath & \text { aga } & - \text { kogo } & \text {-faga }] \\ \text { Me-[re] } & -k \jmath & \text { a } & -k \jmath & - \text { fa } \\ \text { 1SG-PROG } & - \text { go } & \text { PRF } & -g o & - \text { take }\end{array}$

'I am going to take (it)'

d. Mogo-figi-laga nogo rege -digi aga-gogo-logo

$\begin{array}{lllll}\text { [mogo-figi-laga } & \text { nogo } & \text { rigI } & \text {-digi } & \text { aga-gogo-logo] } \\ \text { Mmofra } & \text { no } & \text { re } & \text {-di } & \text { agoro }\end{array}$

PL-child DEF PROG -eat game

'Those children are playing'

In CVN words, the claim about the regular phonology of Akan particularly by Abakah (2005) is that any surface $C V N$ is underlyingly $\mathrm{CV}_{1} \mathrm{NV}_{2}$ where $\mathrm{V}_{2}$ is specified with [+high] feature value as was exemplified in (2) above. This is akin to the claim that a surface $\mathrm{CrV}_{2}$ is $\mathrm{CV}_{1} \mathrm{rV}_{2}$ in the UR, but for nasals, the interconsonantal $\mathrm{V}_{1}$ elides in casual or rapid speech. It was observed in (7) that this deleted high vowel resurfaces in the APL in manipulated $\mathrm{CrV}_{2}$ words. So a $\mathrm{CrV}$ word is manipulated into $\mathrm{CV}_{1} \mathrm{gV}_{1} \mathrm{rV}_{2} \mathrm{gV}_{2}$ in the APL, however, in CVN words, the players manipulate them into $\mathrm{CV}_{1} \mathrm{gV}_{1} \mathrm{~N}$ but not ${ }^{*} \mathrm{CV}_{1} \mathrm{gV}_{1} \mathrm{NgV}_{2}$. The implication of this is that though in the regular phonology of Akan the first nasal of a nasal cluster and a final nasal are considered syllabic, and therefore can stand on their own as was discussed in (2), nasals in the final position do not stand on their own as independent syllables, but rather as inseparable part of the CVN word in the APL. From the pattern observed in (9), $\mathrm{CV}_{1} \mathrm{~N}$ words would have been expected to be manipulated into ${ }^{*} \mathrm{CV}_{1} \mathrm{gV}_{1} \mathrm{NV}_{2} \mathrm{gV}_{2}$ instead of $\mathrm{CV}_{1} \mathrm{gV}_{1} \mathrm{~N}$, the actual form by the speakers. In (10), I provide examples of how CVN words are manipulated in the APL.

(10) Word/morpheme-final nasals

\begin{tabular}{|c|c|c|c|c|}
\hline Maga & -tege & nege & hogo & aga-s\&gem \\
\hline [maga & -tigI & nIgI & hogv & aga-segem] \\
\hline Ma- & te & ne & ho & ascm \\
\hline 1SG.PRF & -hear & 3SG.GEN & self & case \\
\hline
\end{tabular}




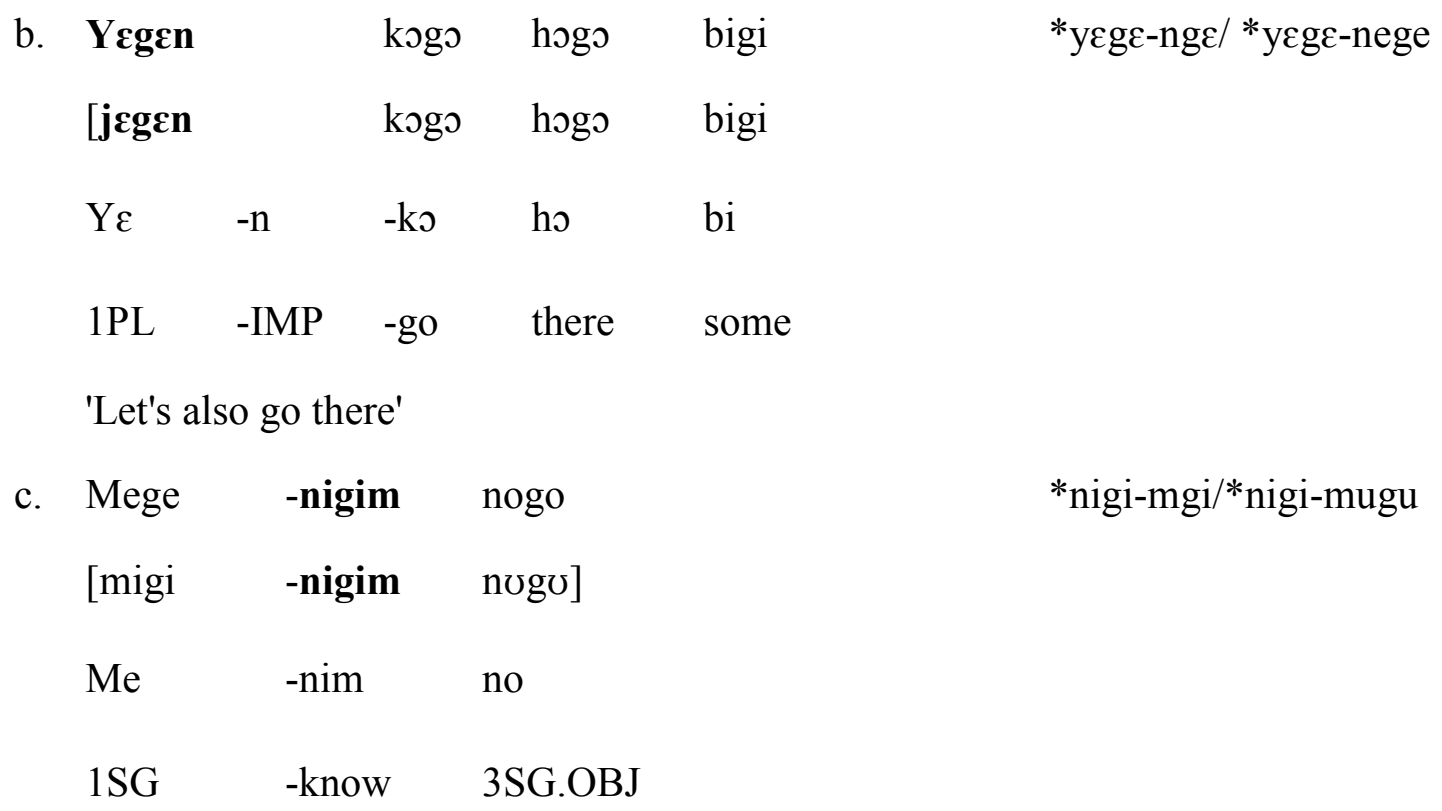

'I know him'

I now turn my attention to a brief discussion of another phonological process in the APL, namely palatalization, which is an assimilatory process.

\subsection{Palatalization}

In the regular Akan phonology, whenever a back consonant such as $/ \mathrm{k}, \mathrm{g}, \mathrm{h}, \mathrm{w} /$ is followed by any of the following front vowels; /e, $\varepsilon, \mathrm{i}, \mathrm{I} / \mathrm{shown}$ in (1) in a syllable, the consonants would usually be expected to undergo full palatalization as in [t6, d $, 6, \mathrm{t}]$ respectively. The palatalization in Akan can simply be stated as follows in (11). In stating the palatalization rule in Akan, I assume Clements/Hume's (1995) Feature Geometry specification for place features for both vowels and consonants as follows: All front vowels and alveolar (anterior) consonants are specified with the feature [coronal]; all velar consonants are specified with [dorsal], while the feature specification for palatals and alveo-palatals, which are complex segments, also is [coronal] (cf. Adomako 2013: 186).

$$
\text { C } \quad \text { V }
$$

(11) Palatalization rule in Akan: $[+$ dorsal $] \rightarrow[+$ coronal, -anterior $] / \ldots[+$ front $]$

There are, however, some few exceptional cases in which this rule fails to apply. These exceptional cases have been observed in the domain of Akan reduplication by researchers such as Christaller (1933); Welmers (1964); Schachter/Fromkin (1968); Marantz (1982); Boadi (1988, 2009); McCarthy \& Prince (1994, 1995); etc. where for example, through the process of $a$-raising, /a/ in the stem verb $k a^{\prime}$ to bite' raises to [I] in the reduplicant [kI] in the reduplicated Akan verb kr.ka'to bite repeatedly', but not t6r.ka, and of recency, in the Akan loanword phonology by Adomako (2013), where an English source word [kerk] 'cake' is adapted into Akan as $k e: k i * k e: t c i / t c e: t c i$. This failure has been termed Underapplication of palatalization in the literature (cf. Marantz 1982; McCarthy/Prince 1994, 1995; Kager 1999; Raimy 2000; Adomako 2013; etc.). A similar lack of palatalization is observed in Akan in the domain of APL where palatalization fails to apply when in the course of manipulating an 
existing word, in the context of a front vowel spreading to the epenthetic site after the epenthetic $[\mathrm{g}]$ has been inserted to form a new CV syllable. An expected palatalization rule, here too, fails to apply. I exemplify this with the following examples in (12).

\section{(12) Failure of palatalization rule}

$\underline{\text { APL form }}$

a.

$\begin{array}{lllll}\text { [migI } & -p \varepsilon g \varepsilon & \text { sege } & \text { migi } & \text {-baga }] \\ \mathrm{Me} & -\mathrm{p} \varepsilon & \mathrm{s} \varepsilon & \text { me } & \text {-ba } \\ 1 \mathrm{SG} & \text {-like } & \text { COMP } & 1 \mathrm{SG} & \text {-come }\end{array}$

'I want to come'
Expected regular form

*Mecke-pedze sectze mecke-baga

b. Mege kege-laga aganigi aga -gyege *mecke tcedke-laga aga-nidzi aga-dzedze

$\begin{array}{lllll}\text { [mIgI } & \text { kıgI-laga } & \text { aganigi } & \text { aga } & \text {-dmIgI] } \\ \mathrm{Me} & \text { kra } & \text { ani } & \text { a } & \text {-gye } \\ \text { 1SG.GEN } & \text { soul } & \text { eye } & \text { PRF } & \text {-collect }\end{array}$

'My soul is satisfied/pleased'

In (12), it can be observed that before the front vowels /i, I, e, $\varepsilon /$, velar stop sounds /k/ and /g/ fail to palatalize into [t6] and [\$] respectively as would be expected based on the phonology of regular Akan.

Having discussed these relevant phonological processes observed in the APL thus far, let us now focus our attention on examining another common phonological process found in the APL, that is, insertion. I will zero in my discussion on insertion inside an existing word or morpheme, which is an uncommon type of insertion in the Akan phonology in general, but well attested in two main contexts in the APL.

\subsection{Insertion}

The [gV] syllable is regularly inserted to the right of the segmented syllables of an existing word or morpheme when playing the APL. The steps in the insertion of the epenthetic [CV], as have already discussed, are that the epenthetic velar stop is attached to the end of a segmented syllable and then the syllable-internal vowel spreads into the epenthetic site. Therefore, for instance, when the syllable-internal vowel is low, it is the low vowel that spreads to the epenthetic site. Similarly, when the syllable-internal vowel is high and front, a high and front vowel spreads.

The process of inserting a segment inside an existing word or morpheme, for the purpose of resyllabification, is not an uncommon process cross-linguistically and particularly in Akan. One common instance of such an insertion comes from the Fante dialect where, for example, 
in some underlying $C U a$ words, where $U$ represents the two back vowels are realized as CU.wa as illustrated in (14).

\section{Insertion of $[w]$ in regular Fante phonology}

\begin{tabular}{|c|c|c|c|c|}
\hline $\mathbf{U R}$ & Fante & Akuapem & Asante & Gloss \\
\hline Akua & $\mathrm{ek}^{\mathrm{w}} \mathrm{u} . \mathbf{w a}$ & $æ k^{\mathrm{y}} \mathrm{i} . \mathrm{a}$ & $æ k^{\mathrm{y}} \mathrm{i} . \mathrm{a}$ & Personal name \\
\hline adua & ed ${ }^{w}$ u.wa & $æ d^{\mathrm{u}} \mathrm{i} . \mathrm{a}$ & $\mathfrak{e d}^{\mathrm{u}} \mathrm{i} . \mathrm{a}$ & beans \\
\hline abua & $e^{\mathrm{w}} \mathrm{u} \cdot \mathbf{w a}$ & $æ b^{\mathrm{w}} \mathrm{u} . \mathrm{a}$ & $æ b^{w} u . a$ & tobacco-pipe \\
\hline aboa & $a b^{w} U . w a$ & $a b^{w} U . a$ & $a b^{w} U . a$ & animal \\
\hline
\end{tabular}

This insertion of the labial-velar glide [w] in the Fante dialects in (14) ensues from the phonological rule of onset creation, though the dialect systematically permits vowels in sequence within words or morphemes. The insertion also blocks the labio-palatalization rule that applies in the Akuapem and Asante dialects from applying in Fante in such context. The insertion of a [CV] syllable inside an existing word or morpheme, however, is what is not attested in Akan in general.

In the APL, there are two main phonological contexts that condition the process of inserting $[\mathrm{g}+\mathrm{V}]$ syllable inside an existing word in during its manipulation. These two contexts are explained below in (15).

\section{(15) The context of insertion inside existing words in the APL}

In the first context, whenever an existing word is CVN in structure, players do not manipulate the word through the regular process of insertion of the $[\mathrm{g}+\mathrm{V}]$ syllable to the end of the segmented syllable as has been observed thus far, but rather inside of the existing morpheme. Below are examples of such insertion in (15ia-b).

(i) Insertion inside CVN morphemes

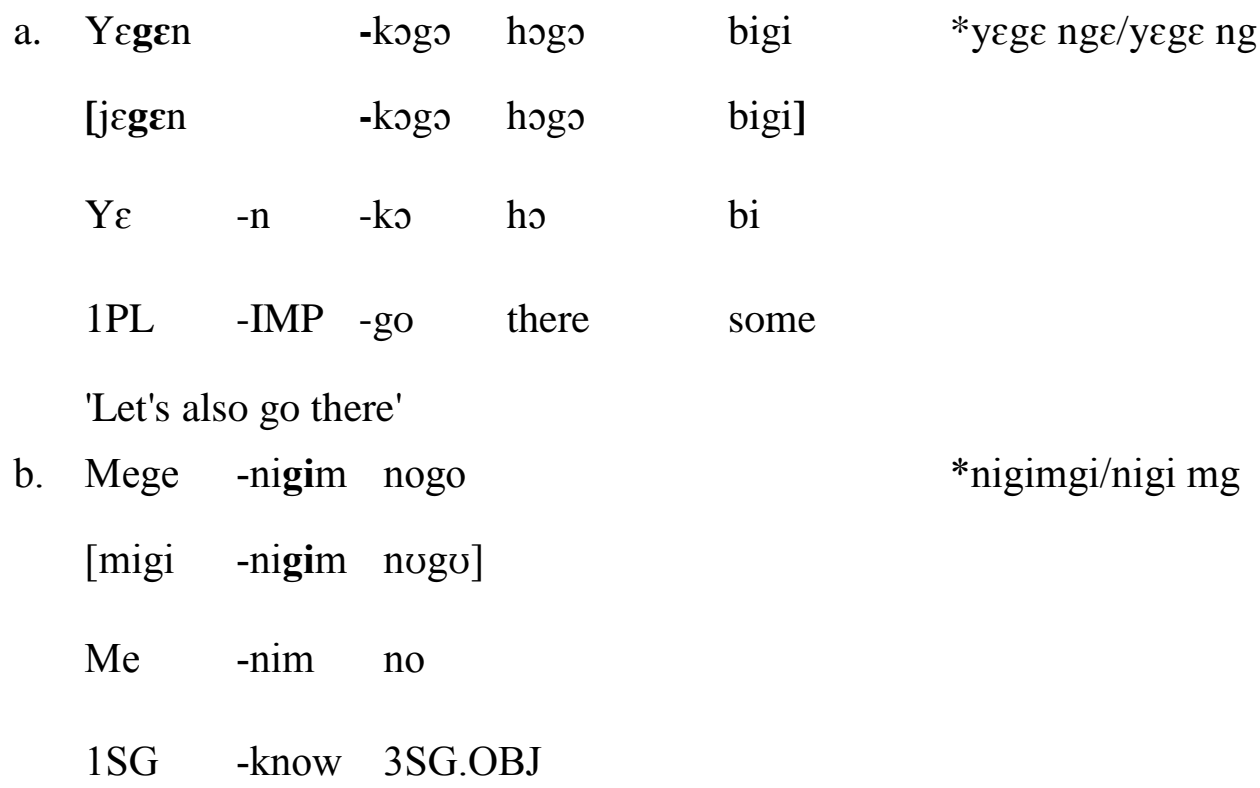

'I know him' 
From (15ia-b), the existing word $y \varepsilon . n$ 'we' is disyllabic in structure, and thus we would have expected two of the epenthetic $[\mathrm{g}+\mathrm{V}]$ syllable inserted into each of the syllables as has been the trend thus far. It is worth noting that in (4) and (5), Emmanuel Nicholas Abakah's (2004) claim about surface $\mathrm{CV}_{1} \mathrm{~N}$ words to be $\mathrm{CV}_{1} \mathrm{NV}_{2}$ in the UR just like surface $\mathrm{CrV}_{2}$, which is $\mathrm{CV}_{1} \mathrm{rV}_{2}$ in the UR was discussed. However, unlike the case of the manipulation of $\mathrm{CrV}_{2}$ words, the deleted $\mathrm{V}_{2}$ of $\mathrm{CV}_{1} \mathrm{NV}_{2}$ never surfaces in the APL. Instead, we realize only one epenthetic syllable inserted inside the manipulated word. Any attempt to syllabify the existing CVN words or morphemes into two independent syllables results in ill-formedness as observed in the data to the right of (15i). As to why *ngi and *mgi are both ill-formed in the manipulated words, I claim in this paper that it is as a result of the fact that nasals lack properties of true nuclei in Akan. As a result of this situation, if the nasal is treated as an independent syllable and the epenthetic velar stop is subsequently attached to it, it would lack vocalism to spread to realize the epenthetic $[\mathrm{g}+\mathrm{V}]$. This would then create highly marked sequences such as *mg or *ng that would be realized as independently manipulated syllables. Among the alternative solutions to this problem that one may propose is that the morpheme or word-internal vowel spread to the following syllable. The problem with this proposal, however, is expressed by the question: Should the vowel spread to the epenthetic syllable premanipulation or post-manipulation of existing words? In either case, the ensuing form of, say, an existing word nim'know', becomes nigi-migi where the vocalic segment in $m i$ is a complete copy of the preceding syllable, specifically from the epenthetic syllable [gi]. However, with our knowledge of how inactive epenthetic segments are, cross-linguistically, to spread features, this line of analysis will be problematic from the onset. Moreover, let us note here that when all the epenthetic syllables are taken out of the manipulated words or morphemes and the segmented syllables reassembled, they should make up meaningful words in the language. This, I suppose, is why players treat these morpheme-final nasals as inseparable parts of existing CVN words and not as independent syllables, hence, the insertion of the $[\mathrm{g}+\mathrm{V}]$ syllable inside an existing word or morpheme.

In the second context where the target word is $\mathrm{C}_{1} \mathrm{~V}_{1} \mathrm{~V}_{2}$ in structure, two different scenarios and their subsequent mode of insertion are observed: $\mathrm{V}_{2}$ is high, or it is nonhigh.

In the first scenario where the $\mathrm{V}_{2}$ is high, the epenthetic $[\mathrm{g}+\mathrm{V}]$ is inserted inside the existing word. That is, an existing $C_{1} V_{1} V_{2}$ is manipulated into $C_{1} V_{1} C_{2} V_{1} V_{2}$. The word- or morphemefinal $\mathrm{V}_{2}$ maintains its final position in the manipulated word. This is illustrated below in (15iia-b).

(ii) Insertion inside CVV words or morphemes

\begin{tabular}{|c|c|c|c|c|}
\hline Ogo & $-p \varepsilon g \varepsilon$ & sege & ogo-gyagae & *gyaga-ege \\
\hline [ogo & $-p \varepsilon g \varepsilon$ & sege & ogo-dzagai] & $*[$ dzaga-IgI $]$ \\
\hline 0 & $-p \varepsilon$ & $\mathrm{S} \varepsilon$ & o-gyae & \\
\hline $3 \mathrm{SG}$ & -like & COMP & 3SG-stop & \\
\hline
\end{tabular}

'S/he wants to stop' 


\begin{tabular}{|c|c|c|c|c|}
\hline Wegei & $\mathrm{y} \varepsilon \mathrm{g} \varepsilon$ & mege & tigi-kyaga & ${ }^{*}$ wege-igi \\
\hline [yegei & $\mathrm{j} \varepsilon \mathrm{g} \varepsilon$ & mIgI & tigi-t6aga & $*$ [yege-igi] \\
\hline Yei & $\mathrm{y} \varepsilon$ & me & tikya & \\
\hline DEM & $\mathrm{COP}$ & 1SG.C & teacher & \\
\hline
\end{tabular}

'This is my teacher'

The question as to why an existing word or morpheme gyae [dar] is manipulated into [dagar] but not *[dzaga-IgI], can be explained by considering what the distributional properties of high vowels is in the regular phonology of Akan. In the Twi dialects of Akan, high vowels never occur in initial position (cf. Dolphyne 2006; Abakah 2004, 2005; among others). No other vowels have such distributional restrictions as do the high vowels. The same wellformedness constraint, it is assumed in the current paper, applies to high vowels in the APL as seen in (15iia-b). To avoid violating this constraint, players of the game treat the entire existing CVV word or morpheme as monosyllabic and manipulate it by inserting inside, but not attaching the epenthetic [CV] syllable to the end, of an existing word. It is also worth noting that the epenthetic syllable is systematically CV hence, the manipulated form of for instance, *dargar would violate that templatic CV structure requirement.

In the second scenario where the $\mathrm{V}_{2}$ is nonhigh, however, the word is manipulated through inserting inside it and not attaching to it as seen in the preceding example. This is so because mid-vowels (both front and back) as well as low vowels, unlike the high vowels, can occupy in word- or morpheme-initial position. This is exemplified as follows;

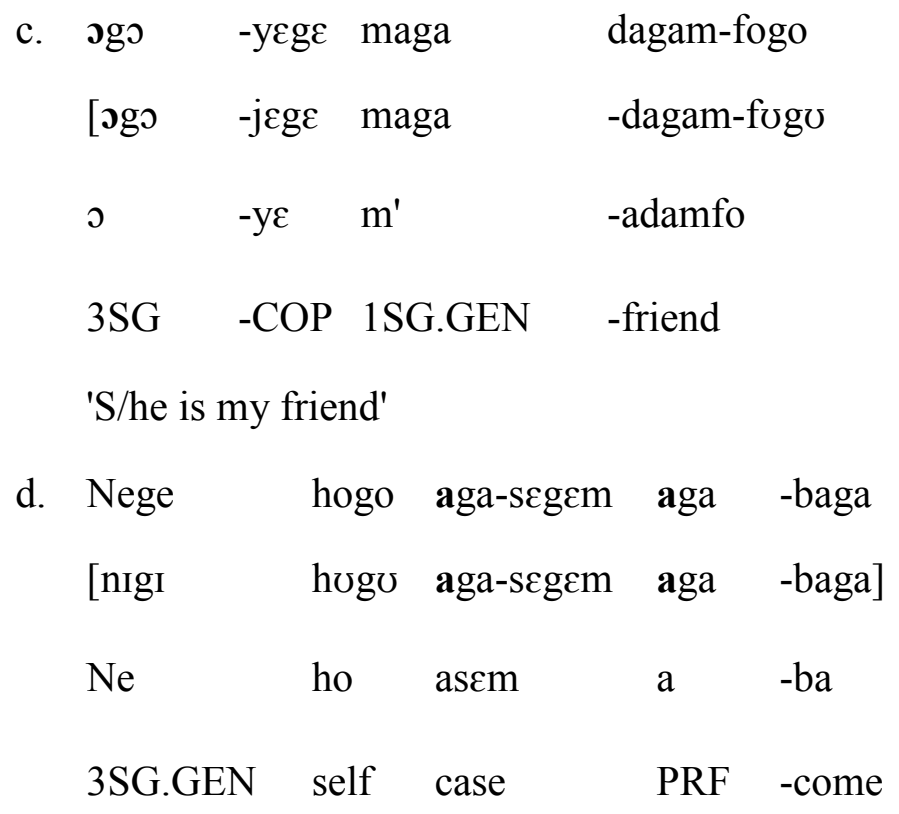

'An issue concerning him has arisen' 


\begin{tabular}{|c|c|c|}
\hline ogo & -wogo & ogo-bugu-ogo \\
\hline [ogo & -wogo & ogo-bugu-ogo] \\
\hline O & -wo & obuo \\
\hline $3 \mathrm{SG}$ & -possess & respect \\
\hline
\end{tabular}

'S/he commands respect'

\section{Conclusion}

This paper has provided a descriptive account of some phonological processes observed in the APL namely, palatalization, insertion, as well as syllabification. It has confirmed the earlier postulation in the literature about the Akan syllable structure particularly with reference to $\mathrm{CrV}$ morphemes. The claim is that all surface $\mathrm{CrV}$ morphemes are underlyingly $\mathrm{CVrV}$ (cf. Schachter/Fromkin 1968; Dolphyne 2006; Abakah 2004; Marfo/Yankson 2008; Marfo 2013; among others). It was observed in this paper that the pre-liquid front high vowel, which is systematically dropped in $\mathrm{CVrV}$ morphemes or words in casual speech in Akan to realize $\mathrm{CrV}$, re-emerges in similar words in the APL. Similarly, in the existing CVN morphemes, it seems players of the game perceive them to be monosyllabic vis-à-vis their disyllabic status in the regular Akan phonology as discussed in $§ 1.2$. Just as in the CrV morphemes where the players inserted the front high vowel in their manipulation, we would have expected the reemergence of the deleted underlying morpheme-final high vowels in the manipulation process to realize them as disyllables. However, those morphemes were not segmented into two syllables before their manipulation.

On the issue of palatalization in Akan, the APL has further opened up the debate as to whether palatalization is still very active in Akan or not. It was observed that a systematic failure of the application of palatalization though palatalizing environment was created in the APL, thus, making the APL another domain in addition to reduplication, loanword where the process fails.

Another observation made in this paper is that the epenthetic [gV], unlike the reduplicant CV of, say, $k r$ of base CV $k a$ 'to bite' in reduplicated verb $k r . k a$ 'to bite continuously', does not add any meaning (whether related or unrelated) to the existing syllable. However, just like in the reduplication of $\mathrm{CV}$ verbal bases in Akan where if the $\mathrm{V}$ is low, it is invariably prespecified with [+high] in the reduplicant (cf. Schachter/Fromkin 1968; Marantz 1982; Lieber 1987; McCarthy/Prince 1995; Kager 1999; Raimy 2000; Dolphyne 2006; Adomako 2012; Abakah 2013; among others), in the APL the C of the epenthetic CV is invariably [dorsal]. I propose a further study into this insertion in the APL to ascertain whether it is a kind of reduplication in Akan where in this case it is CV syllables, and not the entire existing word, that reduplicate.

Finally, I conclude that the APL as a linguistic game, just like the other well-studied domains in Akan, namely reduplication, is a highly productive domain in Akan which can facilitate our understanding of several linguistic phenomena. 


\section{References}

Abakah, Emmanuel Nicholas (2004): "Elision in Fante". Asia \& African Languages and Literatures 4: 181-213.

Abakah, Emmanuel Nicholas (2005): "Phonological analysis of word-final consonants in Akan". Asia \& African Languages and Literatures 5: 47-65.

Abakah, Emmanuel Nicholas (2006): "Where have all the consonantal phonemes of Akan gone?" Journal of Philosophy and Culture 1/2: 21-48.

Abakah, Emmanuel Nicholas (2013): "Vowel replacement patterns in the Mfantse dialect of Akan". Journal of Universal Language 14/2: 7-51.

Adomako, Kwasi (2008): Vowel epenthesis and consonant deletion in loanwords: a study of Akan. Master's thesis, University of Tromso, Norway.

Adomako, Kwasi (2012): "Verbal Nominalization as derivational process: The case of Akan". Ghana Journal of Linguistics 1/2: 43-64.

Adomako, Kwasi (2013): "Underapplication in Akan loanword adaptation". International Journal of Linguistics 5/5: 174-197.

Agyekum, Kofi (1996): Akan verbal taboos in the context of the ethnography of communication. Master's thesis, University of Trondheim (Norway).

Agyekum, Kofi (2009): "Ethnography of Akan speech play". Nordic Journal of African Studies 30:47-81.

Boadi, Lawrence Addai (1988): "Problems of palatalization in Akan". Journal of West African Languages 38/1: 3-16.

Boadi, Lawrence Addai (2009): A Comparative Phonological Study of Some Verbal Affixes in Seven Volta Comoe Languages of Ghana. Accra: Black Mask.

Christaller, Johann Gottlieb (1875/1933): A Grammar of the Asante and Fante Language Called Tshi. Upper Saddle River: Gregg Press.

Clements, George Nick/Hume, Elizabeth (1995): "Internal organization of speech sounds". In:

Goldsmith, John A. (ed.): The Handbook of Phonological Theory. Hoboken, Blackwell: 245306.

Conklin, Harold C. (1956): "Tagalong Speech Disguise". Language 32: 136-139.

Conklin, Harold C. (1959): "Linguistic play in its cultural context". Language 35: 631-636.

Decamp, David (1970): "Iteration in Jamaican Creole". Paper presented at the University of Texas Faculty Sociolinguistics Seminar.

Dolphyne, Florence Abena (2006): The Akan (Twi-Fante) Language: Its sound systems and tonal structure. Accra: Woeli.

Ghana Statistical Service (2012): 2010 Population and Housing Census: Summary of Final Results.

http://www.statsghana.gov.gh/docfiles/2010phc/Census2010_Summary_report_of_final_re sults.pdf [20.06.2012].

Haas, Mary Rosamund (1957): "Thai word games". Journal of American Forklore 70: 173175.

Haas, Mary Rosamund (1967): "A taxonomy of disguised speech". Paper presented at the Annual Meeting of the Linguistic Society of America.

Haas, Mary Rosamund (1969): "Burmese disguised speech". Bulletin of the Institute of History and Philology (Academica Sinica) 39: 277-285.

Halle, Morris (1962): "Phonology in Generative Grammar". Word 18: 54-72. 
Hombert, Jean-Marie (1973): "Speaking backwards in Bakwiri". Studies in African Linguistics 4/3: 227-236.

Kager, René. (1999): Optimality Theory. New York: Cambridge University Press. (Cambridge Textbooks in Linguistics).

Lehiste, Ilse (1985): "An Estonian word game and the phonematic status of long vowels". Linguistic Inquiry 16/3: 490-492.

Lieber, Rochelle (1987): An Integrated Theory of Autosegmental Processes. Albany: State University of New York Press.

Marantz, Alec (1982): "Re Reduplication". Linguistic Inquiry 13/3: 435-482.

Marfo, Charles/Yankson, Solace (2008): "The structure of the CCV syllable of Akan". Concentric: Studies in Linguistics 34/2: 85-100.

Marfo, Charles Ofosu (2013): "Optimizing structure: the case of the 'CrV' syllable of Akan". Ghana Journal of Linguistics 2/1: 63-78.

McCarthy, John/Prince, Alan (1994): "The emergence of the unmarked: Optimality Theory in Prosodic Morphology". In: Gonzàlez, Mercè (ed.): Proceedings of North East Linguistic Society 24. Amherst, GLSA: 333-379.

McCarthy, John/Prince, Alan (1995): "Faithfulness and reduplicative identity". In: Beckman, Jill/Walsh-Dickey, Laura/Urbanczyk, Suzzane (eds.): Papers in Optimality Theory. University of Massachusetts Occasional Papers 18. Amherst, GLSA: 249-384.

Raimy, Eric (2000): The Phonology and Morphology of Reduplication. Berlin/New York: de Gruyter. (Studies in Generative Grammar 52).

Sanches, M. (1968): "A study of Japanese Inflectional Morphology". Paper presented at a jointmeeting of the American Ethnological Society and the Southern Anthropological Association.

Schachter, Paul/Fromkin, Victoria (1968): A Phonology of Akan: Akuapem, Asante \& Fante. Los Angeles: University of California. (UCLA Working papers in Phonetics 9).

Sherzer, Joel (1970): "Talking backwards in Cuna: the sociological reality of phonological Descriptions". Southwestern Journal of Anthropology 26/4: 343-353.

Sherzer, Joel (1976): "Play languages: implications for (socio) linguistics". In: KirshenblattGimblett, Barbara (ed.): Speech Play. Research and Resources for Studying Linguistic Creativity. Philadelphia, University of Pennsylvania Press: 19-36.

Sherzer, Joel (1985): "Puns and jokes". In: Van Dijk, Teun A. (ed.): Handbook of Discourse Analysis Volume 3. Discourse and Dialogue. London, Academic Press: 213-221.

Welmers, William Everett (1946/1966): A Descriptive Grammar of Fanti. Reprint. New York: Kraus Repr. Corp. 